\title{
Arteriovenous malformations in multiple organs in a patient presenting with hereditary haemorrhagic telangiectasia
}

\author{
Rakesh Kodati, Kuruswamy Thurai Prasad ${ }^{\bullet}$
}

Department of Pulmonary Medicine, Postgraduate Institute of Medical Education and Research, Chandigarh, India

Correspondence to Dr Kuruswamy Thurai Prasad, docktp@gmail.com

Accepted 25 April 2019

\section{DESCRIPTION}

A 30-year-old woman presented with exertional breathlessness of 1-month duration. On evaluation at the outpatient clinic, she did not have pallor, cyanosis, clubbing or pedal oedema. Auscultation of the chest revealed normal breath sounds, and cardiovascular examination was normal. Oxygen saturation by pulse oximetry was $94 \%$, and arterial blood gas analysis revealed hypoxaemia while breathing ambient air (partial pressure of arterial oxygen $\left(\mathrm{PaO}_{2}\right)$ of $58 \mathrm{~mm} \mathrm{Hg}$ ). Chest radiograph showed rounded opacities in the left lung (figure 1A). Contrast-enhanced CT of the chest suggested that these lesions were of vascular origin (figure 1B), which was confirmed by CT pulmonary angiography to be pulmonary arteriovenous malformations (AVMs) (figure 1C).

The patient was hospitalised for a detailed evaluation. A meticulous history was obtained during which she admitted to having multiple episodes of spontaneous epistaxis since childhood, for which she had not sought any medical attention. Careful physical examination revealed tiny telangiectasias over the tongue and lips (figure 2A,B). Upper gastrointestinal endoscopy revealed telangiectasias in the lower oesophagus (figure 2C). Nasal endoscopy was normal. MRI of the brain did not reveal any cerebral AVMs. However, multiple chronic infarcts were noted in the right frontal lobe and cerebellum. A 'definite' diagnosis of hereditary haemorrhagic telangiectasia (HHT), also known as Osler-Weber-Rendu syndrome, was made as she fulfilled three of the four Curacao criteria (spontaneous and recurrent epistaxis, multiple mucocutaneous telangiectasias and visceral AVMs). ${ }^{1}{ }^{2}$ Although her family history revealed that her mother had similar episodes of recurrent epistaxis and had

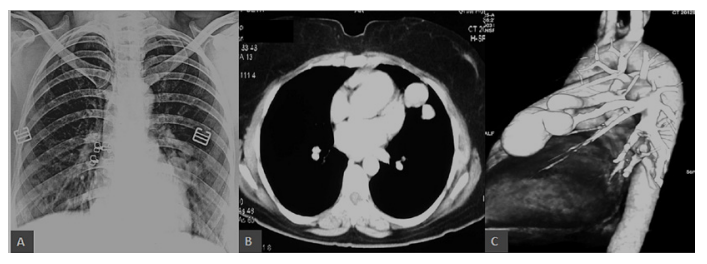

Figure 1 Chest radiograph showing well-defined, rounded, homogenous opacities in the left paracardiac region (A). The lesions show intense contrast enhancement on CT scan suggesting vascular origin (B). CT pulmonary angiogram demonstrating two arteriovenous malformations arising from the left pulmonary artery (C).

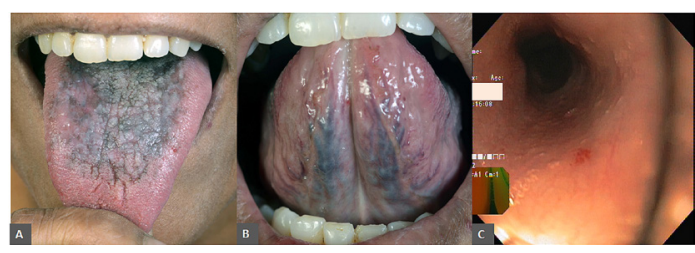

Figure 2 Multiple dot-like telangiectatic lesions are visible on the dorsal and ventral surfaces of the tongue and lips (A and B). Upper gastrointestinal endoscopy showing telangiectasia in the lower oesophagus (C).

succumbed to cerebral haemorrhage a year back, the fourth criterion (first-degree relative with HHT according to these criteria) could not be met with certainty as we lacked sufficient clinical details. She did not have any siblings. The patient underwent successful percutaneous transcatheter embolisation of the pulmonary AVMs, following which she had significant clinical improvement. She was advised to follow up after 6-12 months for re-evaluation.

More than two-thirds of the patients presenting with pulmonary AVMs have underlying HHT, which is an autosomal dominant condition associated with vascular malformations. ${ }^{3}$ The index case highlights the tendency of HHT to have multiorgan involvement that might require multidisciplinary management involving several disciplines including otorhinolaryngology, pulmonology, neurosurgery, gastroenterology and hepatology. Experts recommend screening for pulmonary, hepatic and cerebral AVMs in patients with HHT using bubble contrast echocardiography, Doppler ultrasonography and MRI brain, respectively. ${ }^{2}$ In addition, annual measurement of haemoglobin should be undertaken in such patients since gastrointestinal bleeding in HHT is usually mild and intermittent leading to anaemia rather than overt bleeding. Transcatheter embolotherapy is the current standard of care in most patients with pulmonary AVMs $\geq 3 \mathrm{~mm}$ in diameter. ${ }^{34}$ Surgical resection of pulmonary AVMs is usually reserved for patients with intrapleural rupture of AVM, and those who fail or have contraindications to embolotherapy. In contrast, embolotherapy is not recommended for hepatic AVMs as the procedure is associated with unacceptable morbidity and mortality. Instead, patients with clinically significant hepatic AVMs should be referred for liver transplantation. The management of cerebral vascular malformations is more complicated and requires individualised 
treatment decisions for using embolotherapy, microsurgery and

\section{Learning points}

- Patients in whom pulmonary arteriovenous malformations (AVMs) are diagnosed should be carefully evaluated for hereditary haemorrhagic telangiectasia (HHT) since they can have multisystem involvement (upper respiratory tract, central nervous system and gastrointestinal tract) without any symptoms.

- Since most patients with HHT needs multidisciplinary management, wherever feasible, they should be referred to centres with a dedicated HHT clinic or other experienced tertiary centres.

- Family members of patients with HHT should be evaluated for this condition as AVMs may result in life-threatening complications like bleeding, paradoxical embolisation and pulmonary hypertension. stereotactic radiation.

Contributors RK: involved in patient management, acquisition and interpretation of data and drafted and revised the manuscript. KTP: involved in patient management, interpretation of data and drafted and revised the manuscript.

Funding The authors have not declared a specific grant for this research from any funding agency in the public, commercial or not-for-profit sectors.

Competing interests None declared.

Patient consent for publication Obtained.

Provenance and peer review Not commissioned; externally peer reviewed.

\section{REFERENCES}

1 Muthu V, Sehgal IS, Agarwal R, et al. A 32-year-old-man with a severe headache, visual loss, and nodular pulmonary opacities. Chest 2016;150:e137-e141.

2 Faughnan ME, Palda VA, Garcia-Tsao G, et al. International guidelines for the diagnosis and management of hereditary haemorrhagic telangiectasia. J Med Genet 2011;48:73-87.

3 Faughnan ME, Granton JT, Young LH. The pulmonary vascular complications of hereditary haemorrhagic telangiectasia. Eur Respir J 2009;33:1186-94.

4 Dupuis-Girod S, Cottin V, Shovlin CL. The lung in hereditary hemorrhagic telangiectasia. Respiration 2017:94:315-30.

Copyright 2019 BMJ Publishing Group. All rights reserved. For permission to reuse any of this content visit https://www.bmj.com/company/products-services/rights-and-licensing/permissions/

BMJ Case Report Fellows may re-use this article for personal use and teaching without any further permission.

Become a Fellow of BMJ Case Reports today and you can:

- Submit as many cases as you like

- Enjoy fast sympathetic peer review and rapid publication of accepted articles

- Access all the published articles

- Re-use any of the published material for personal use and teaching without further permission

For information on Institutional Fellowships contact consortiasales@bmjgroup.com

Visit casereports.bmj.com for more articles like this and to become a Fellow 